Journal of Molecular Structure, 29 (1975) 153-161

(0) Elsevier Scientific Publishing Company, Amsterdam - Printed in The Netherlands

\title{
A STUDY OF THE MOLECULAR STRUCTURE OF MONOCHLORO- ACETIC ACID BY MEANS OF GAS ELECTRON DIFFRACTION
}

\author{
J. L. DERISSEN and J. M. J. M. BIJEN \\ Department of General Chemistry, Section of Structural Chemistry, Transitorium 3, \\ Padualaan 8, Rijksuniversiteit Utrecht (The Netherlands)
}

(Received 2 April 1973; revised 24 October 1974)

\section{ARSTRACT}

The results of an interpretation of the gas electron diffraction pattern of monochloroacetic acid at $170^{\circ} \mathrm{C}$ and a microwave investigation by Van Eijck et al. from this laboratory were combined. Three conformations with respect to internal rotation around the $\mathrm{C}-\mathrm{C}$ bond were found, viz. $56 \%$ of a conformation with $C_{s}$ molecular symmetry and the $\mathrm{C}-\mathrm{Cl}$ bond eclipsed with the $\mathrm{C}=\mathrm{O}$ bond, $30 \%$ of a conformation with the $\mathrm{CH}_{2} \mathrm{Cl}$ group rotated $131^{\circ}$ from the former position and the remaining $14 \%$ of a conformation with $79^{\circ}$ rotation of the $\mathrm{CH}_{2} \mathrm{Cl}$ group. The bond lengths and the bond angles determined by means of this procedure are (standard deviations in parentheses): $\mathrm{C}-\mathrm{Cl}: 1.778(0.005)$, $C-C: 1.508(0.006), C=0: 1.223(0.004), C-O: 1.352(0.005), C-H: 1.09(0.02), 0-H:$ $0.97(0.015) \mathrm{A} ; \mathrm{C}-\mathrm{C}=\mathrm{O}: 126.1(0.5), \mathrm{C}-\mathrm{C}-\mathrm{O}: 110.6(0.4), \mathrm{C}-\mathrm{C}-\mathrm{Cl}: 112.5(0.4), \mathrm{C}-\mathrm{O}-\mathrm{H}:$ 105.8(1.1 $)^{\circ}$. A conformational distribution obtained by means of $\mathrm{CNDO} / 2$ calculations is not in agreement with our experimental radial distribution.

\section{INTRODUCTION}

In our research program on internal rotation around $\mathrm{C}-\mathrm{C}$ bonds in carboxylic acids [1-3], the molecular structure of chloroacetic acid is now being studied. At the present stage an interpretation of the microwave spectrum by van Eijck et al. [4] has revealed the presence of a planar trans conformation, with the chlorine atom lying in the carboxylic plane eclipsed with the carbonyl group. However, the microwave spectrum allows the presence of one or more other conformations, which could not yet be identified. It was hoped to obtain additional information on these conformations by means of gas electron diffraction experiments at a temperature sufficiently high to avoid intermolecular hydrogen bonded species.

\section{EXPERTMENTAL AND DATA PROCESSING}

$60 \mathrm{kV}$ electron diffraction experiments with a sample of chloroacetic acid from Analar (>99.0\%) were done at $170^{\circ} \mathrm{C}$ nozzle temperature on the Balzers Eldigraph KDG2 electron diffraction unit [5] at the Rijksuniversiteit 
of Leiden. The electron wavelength was calibrated with TICl powder diffraction data and a $3 \%$ correction was applied to yield the correct $r_{\mathrm{g}}(1)$ values for $\mathrm{CO}_{2}[6]$.

Diffraction photographs were taken at camera heights of 1000, 500, 250 and $110 \mathrm{~mm}$. Owing to the extreme corrosiveness of the compound the nozzle system was affected severely and became clogged repeatedly, causing an irregular gas stream. Also an unusually large background scattering was observed. In spite of many efforts, the molecular intensities obtained for the compound were less accurate than usual.

The data reduction procedure described in ref. 7 was followed. We used the scattering factors of Cox and Bonham [8] and we applied empirical background corrections. The molecular intensities, modified with the function $s /\left(f_{c} f_{\mathrm{Cl}}\right)$, ranging from $s=1.625$ to $31.0 \AA^{-1}$, are listed in Table 1 . The unlevelled radial distribution function calculated from these data is shown in Fig. 1.

\section{TABLE 1}

Observed molecular intensities for monochloroacetic acid

$100 \mathrm{~mm}$ camera height, $s=1.625(0.125) 7.125 \mathrm{~A}^{-1}$, scale $=808.1$

$\begin{array}{rrrrrrrrrr}\prime-73 & -124 & -311 & -447 & -529 & -520 & -512 & -500 & -428 & -376 \\ -344 & -328 & -333 & -374 & -380 & -453 & -531 & -596 & -653 & -728 \\ -788 & -823 & -798 & -719 & -555 & -351 & -97 & 157 & 355 & 496 \\ 625 & 729 & 753 & 717 & 671 & 660 & 634 & 608 & 552 & 486 \\ 434 & 367 & 285 & -137 & 5 & & & & & \end{array}$

$500 \mathrm{~mm}$ camera height, $s=3.75(0.25) 15.25 \mathrm{~A}^{-1}$, scale $=351$

$\begin{array}{rrrrrrrrrr}-290 & -360 & -351 & -266 & -154 & 52 & 249 & 328 & 321 & 280 \\ 236 & 211 & 169 & 84 & -76 & -197 & -200 & -129 & 8 & 85 \\ 100 & 19 & -104 & -207 & -250 & -222 & -168 & -116 & 11 & 196 \\ 350 & 392 & 374 & 220 & 0 & -200 & -290 & -351 & -275 & -137 \\ -60 & 21 & 100 & 177 & 148 & 125 & 18 & & & \end{array}$

$250 \mathrm{~mm}$ camera height, $s=9.00(0.25) 25.00 \mathrm{~A}^{-3}$, scale $=213$

$\begin{array}{rrrrrrrrrr}16 & -49 & -113 & -160 & -155 & -134 & -63 & 23 & 140 & 225 \\ 265 & 213 & 106 & -26 & -125 & -181 & -176 & -132 & -89 & -56 \\ 5 & 72 & 112 & 100 & 62 & 18 & -39 & -41 & -40 & -13 \\ 34 & 54 & 19 & 5 & -34 & -36 & -33 & -6 & 26 & 33 \\ 22 & 27 & -13 & -48 & -64 & -48 & -34 & -24 & -14 & 22 \\ 52 & 86 & 77 & 81 & 47 & 23 & 7 & -27 & -62 & -76 \\ -75 & -79 & -44 & -24 & -9 & & & & & \end{array}$

$110 \mathrm{~mm}$ camera height, $s=25.00(0.25) 31.00 \mathrm{~A}^{-1}$, scale $=806$

\begin{tabular}{rrrrrrrrrr}
-7 & 82 & 169 & 180 & 208 & 184 & 142 & 34 & -17 & -100 \\
-140 & -94 & -85 & -46 & 111 & 156 & 112 & 66 & -53 & -88 \\
-74 & -117 & -120 & -141 & -60 & & & & & \\
\hline
\end{tabular}




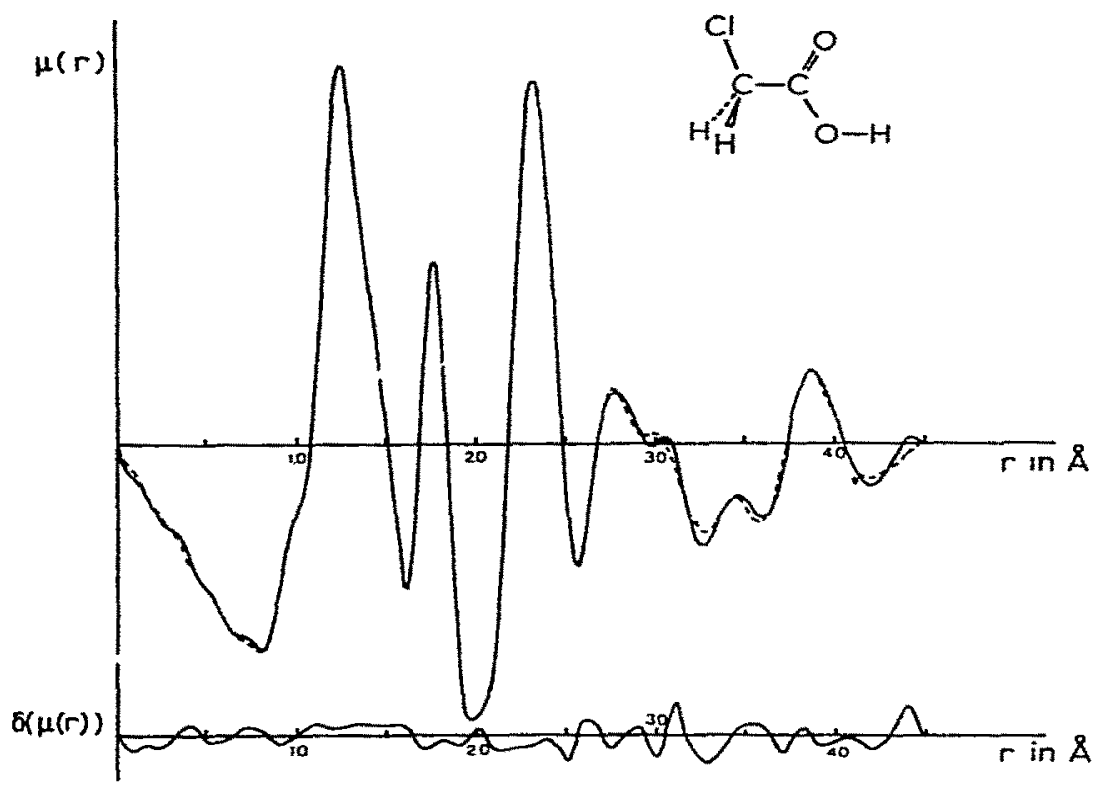

Fig. 1. Unlevelled radial distribution for monochloroacetic acid. Damping factor $\mathrm{e}^{-0.001 \mathrm{~s}^{2}}$; $(-)$ observed, (-.--) calculated. The difference curve was multiplied by a facter 2.37.

\section{STRUCTURE ANALYSIS}

Analogy of bond lengths, bond angles and vibrational amplitudes with those in monofluoroacetic acid [1], acetic acid [2] and propionic acid [2] made the interpretation of the experimental radial distribution function (RDF) up to $2.7 \AA$ relatively easy.

To get an insight in the conformations with respect to internal rotation of the $\mathrm{CH}_{2} \mathrm{Cl}$ group around the $\mathrm{C}-\mathrm{C}$ bond, the $\mathrm{O} \cdots \mathrm{Cl}$ distances were calculated as function of this rotation (see Fig. 2), and these distances were compared with the RDF from 2.7 to $4.0 \AA$. It could be concluded that at least two conformations are present in large fractions, viz. conformations with $\alpha \approx 0^{\circ}$ and $\alpha \approx 130^{\circ}$ (we define the internal rotational angle $\alpha=0^{\circ}$ when the $\mathrm{C}-\mathrm{Cl}$ bond is eclipsed with the $\mathrm{C}=\mathrm{O}$ bond and call this the trans position [1]). However, calculated RDF's showed that the peak at $3.45 \AA$ remained to be accounted for and that the calculated peaks at 3.0 and $3.85 \AA$ were too high. Therefore a third conformation had to be introduced, with $\alpha \approx 80^{\circ}$. A conformation with $\alpha \approx 90^{\circ}$ has a nearly identical set of $\mathrm{O} \cdot \mathrm{C}$ distances but was ruled out by the subsequent least-squares refinements.

In contrast to the findings in monofluoroacetic acid [1] the occurrence of a conformation with $\alpha \approx 180^{\circ}$ is not in agreement with the RDF. The presence of hydrogen bonded dimers could also be excluded: from the peak heights in the RDF it is seen that there is no contribution of the $\mathrm{O} \cdots \mathrm{O}$ 


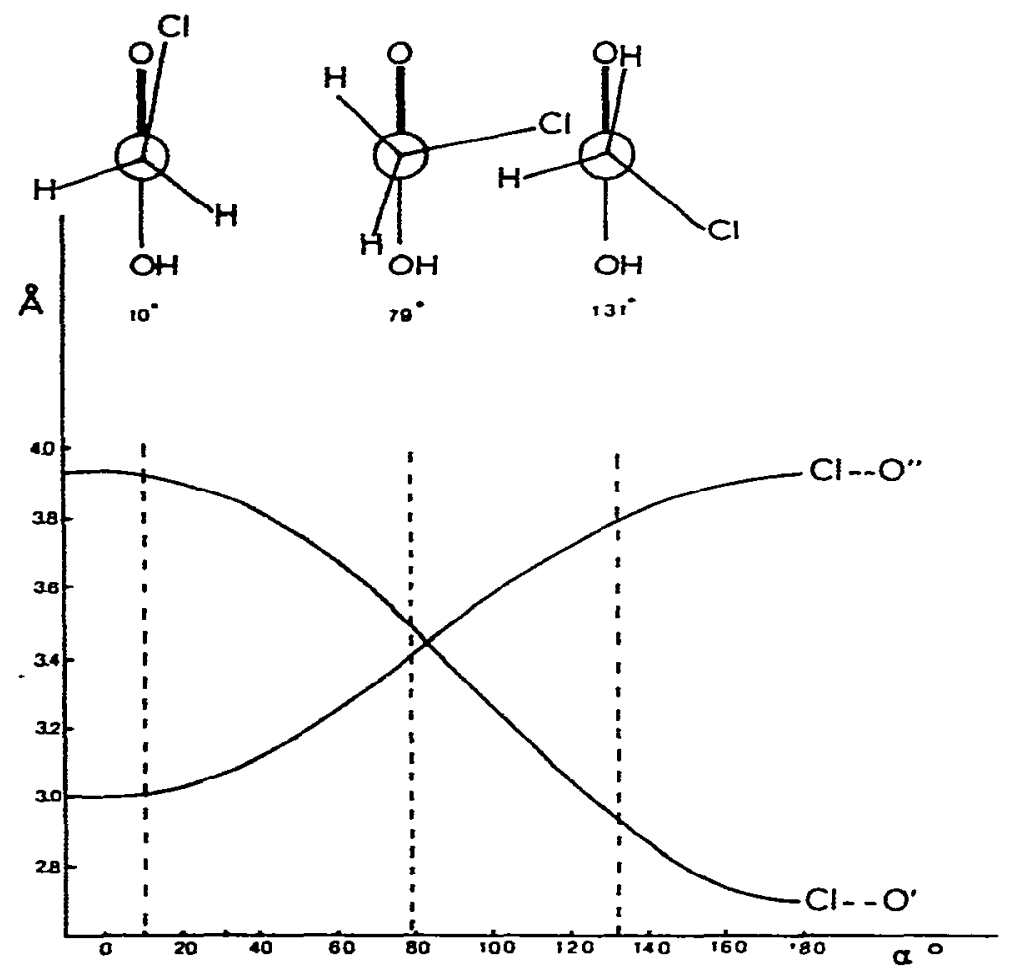

Fig. 2. Variation of $\mathrm{O}--\mathrm{Cl}$ distances with conformational angle $\alpha$, and Newman projections of the three conformations described in the text.

distances of $2.65,3.2$ and $3.7 \AA$ expected for these dimers. The bond lengths, the bond angles and the vibrational amplitudes for all distances except $\mathrm{Cl} \cdots \mathrm{O}$ were assumed not to vary with the conformational angles. The hydrogen atom parameters were assumed to have fixed values, the low contribution of the hydrogen atoms to the molecular intensity inhibited the determination of their positions. The results of least-squares refinements of the parameters describing the molecular model with the above three conformations are presented in Tables 2 and 3. In order to correct for the effect of correlation between the intensity data [9], the standard deviations resulting from the normal equations were multiplied by a factor of 2 . In addition a $1 \%$ uncertainty in the wavelength has been included.

After completion of this refinement the results of the microwave analysis of van Eijck et al. [4] became available. The inertia moments and substitution coordinates of the $\mathrm{Cl}$ and the hydroxyl $\mathrm{H}$ atoms for the planar trans conformation are given in Table 4. The problem of the difference of $r_{\mathrm{s}}$ and $\dot{r}_{\mathrm{g}}(1)$ structures obtained by microwave spectroscopy and electron diffraction respectively was realized. A thorough treatment [10], however, is in this case impossible with the limited amount of data available. Therefore a least-squares 


\section{TABLE 2}

Results from least-squares refinements of model parameters for monochloroacetic acid, using only electron diffraction data and for combined electron diffraction data and microwave spectroscopy data

\begin{tabular}{|c|c|c|c|c|}
\hline \multirow[t]{2}{*}{ Parameter } & \multicolumn{2}{|c|}{ Electron diffraction } & \multicolumn{2}{|c|}{$\begin{array}{l}\text { Electron diffraction }+ \\
\text { Microwave spectroscopy }\end{array}$} \\
\hline & Value & Standard deviation & Value & Standard deviation \\
\hline $\mathrm{C}-\mathrm{Cl}$ & $1.778 \mathrm{~A}$ & $0.005 \mathrm{~A}$ & $1.778 \mathrm{~A}$ & $0.005 \AA$ \\
\hline$C-C$ & 1.509 & 0.006 & 1.508 & 0.006 \\
\hline $\mathrm{C}=\mathrm{O}$ & 1.224 & 0.004 & 1.223 & 0.004 \\
\hline $\mathbf{C}-\mathbf{O}$ & 1.354 & 0.005 & 1.352 & 0.005 \\
\hline $\mathbf{C}-\mathbf{H}$ & 1.09 & 0.02 & 1.09 & 0.02 \\
\hline $\mathbf{O}-\mathbf{H}$ & 0.983 & a & 0.97 & 0.015 \\
\hline $\mathrm{C}-\mathrm{C}=\mathrm{O}$ & $126.2^{\circ}$ & $0.5^{\circ}$ & $126.1^{\circ}$ & $0.5^{\circ}$ \\
\hline $\mathrm{C}-\mathrm{C}-\mathrm{O}$ & 110.7 & 0.4 & 110.6 & 0.4 \\
\hline $\mathrm{C}-\mathrm{C}-\mathrm{Cl}$ & 112.8 & 0.6 & 112.5 & 0.4 \\
\hline $\mathbf{C}-\mathbf{O}-\mathbf{H}$ & 106 & a & 105.8 & 1.1 \\
\hline $\mathbf{C}-\mathbf{C}-\mathrm{H}$ & 109.5 & a & 109.5 & a \\
\hline $\mathbf{H}-\mathbf{C}-\mathbf{H}$ & 109.5 & a & 109.5 & $\mathbf{a}$ \\
\hline$\alpha(I)$ & $10^{\circ}$ & $10^{\circ}$ & $10^{\circ}$ & $\mathbf{a}$ \\
\hline$\alpha($ II $)$ & 132 & 4 & 131 & 4 \\
\hline$\alpha(\mathrm{III})$ & 78 & 6 & 79 & 4 \\
\hline $\mathscr{q}(I)$ & $51 \%$ & 9 & $56 \%$ & 6 \\
\hline \%(II) & 33 & 9 & 30 & 6 \\
\hline$\%(I I I)$ & 16 & & 14 & \\
\hline scale $100 \mathrm{~cm}$ & 0.0813 & 0.00274 & 0.08118 & 0.00280 \\
\hline scale $50 \mathrm{~cm}$ & 0.00352 & 0.00014 & 0.00353 & 0.00014 \\
\hline scale $25 \mathrm{~cm}$ & 0.00213 & 0.00012 & 0.00214 & 0.00012 \\
\hline scale $11 \mathrm{~cm}$ & 0.00848 & 0.000208 & 0.00908 & 0.000252 \\
\hline $\begin{array}{l}\Sigma w \Delta^{2} \\
R^{\mathrm{b}}\end{array}$ & $\begin{array}{l}110.5 \\
0.094\end{array}$ & & $\begin{array}{r}109.5 \text { (elect } \\
0.096(\mathrm{el})\end{array}$ & $\begin{array}{l}\text { diffraction alone) } \\
\text { con diffraction alone }\end{array}$ \\
\hline
\end{tabular}

aThis parameter was assumed and fixed in the refinements.

${ }^{b} R$ is defined as $\Sigma\left|I_{\text {obs }}-I_{\text {calc }}\right| / \Sigma I_{\text {obs }}$.

refinement was done in which the microwave data were assigned weights according to expected difference of 0.005 and $0.003 \AA$ between $r_{\mathrm{s}}$ and $r_{\mathrm{g}}(1)$ values of $\mathrm{C}-\mathrm{H}$ and $\mathrm{C}-\mathrm{Cl}$ bonds respectively, and the electron diffraction intensities were given their usual weights, based upon experimental errors. The results of this procedure, now including refined values for the $\mathrm{O}-\mathrm{H}$ bond length and the $\mathrm{C}-\mathrm{O}-\mathrm{H}$ bond angle, are shown in Tables 2 and 4 . It was realized that a continuous distribution of conformations gives an even better agreement between calculated and observed molecular intensities. Attempts to determine it soon showed that the parameters describing the distribution were very ill determined and that they showed a large correlation with the vibrational amplitudes. 
TABLE 3

Root mean square amplitudes of vibration from electron diffraction data refinement of monochloroacetic acid

\begin{tabular}{lll}
\hline Distarce & Value & Standard deviation \\
\hline C-C & 0.062 A & 0.004 A \\
C-C & 0.054 & 0.007 \\
C-O & 0.051 & 0.007 \\
C $=$ O & 0.043 & 0.007 \\
C-H & 0.078 & $a$ \\
O-H & 0.070 & $a$ \\
C - - O & 0.054 & 0.010 \\
O - - O & 0.051 & 0.010 \\
O - - C & 0.093 & 0.009 \\
C - - - O short & 0.128 & 0.015 \\
C - - - O medium & 0.100 & $a$ \\
C - - O long & 0.096 & 0.024 \\
all other & 0.12 & 2 \\
\hline
\end{tabular}

aThis means that this parameter was assumed and kept constant during the refinements.

TABLE 4

Microwave data used in the least-squares refinements

\begin{tabular}{|c|c|c|}
\hline $\begin{array}{l}\text { Experimental } \\
\text { Microwave data }\end{array}$ & $\begin{array}{l}\text { Calculated } \\
\text { Microwave data }\end{array}$ & $\begin{array}{l}\text { Assigned } \\
\text { Standard deviation }\end{array}$ \\
\hline $\begin{array}{l}I_{a}=48.0630 \mathrm{amu} \mathrm{A}^{2} \\
I_{b}=214.9294 \\
b_{\mathrm{H}}^{2}=-0.0003 \mathrm{~A}^{2} \\
a_{\mathrm{H}}^{2}=8.1100 \\
b_{\mathrm{CI}}^{2}=0.0016 \\
a_{C I}^{2}=3.0443\end{array}$ & $\begin{array}{l}48.13 \text { amu } A^{2} \\
216.48 \\
0.0011 A^{2} \\
8.087 \\
0.0011 \\
3.0632\end{array}$ & $\begin{array}{l}0.24 \mathrm{amu} A^{2} \\
1.08 \\
0.001 \AA^{2} \\
0.03 \\
0.0005 \\
0.01\end{array}$ \\
\hline
\end{tabular}

\section{DISCUSSION}

The structural parameters of monochloroacetic acid, derived from the electron diffraction data alone, and those from the combined refinement of the electron diffraction data and the microwave data for the planar trans conformation, show a difference no greater than one standard deviation. The bond lengths and bond angles all have expected values in relation to those in acetic and propionic acid monomer [2], and those in monofluoroacetic acid [1].

The electron diffraction molecular intensity could well be described with a molecular model with three conformations due to hindered internal rotation of the $\mathrm{CH}_{2} \mathrm{Cl}$ group around the $\mathrm{C}-\mathrm{C}$ bond. The trans conformation $\left(\alpha \approx 10^{\circ}\right)$ 
present in an amount of 56\%, was already found in the microwave investigation of van Eijck et al. [4]. The value of $10^{\circ}$ found for the conformational angle in our refinements may be interpreted as an average angle of displacements from the $\alpha \approx 0^{\circ}$ position due to oscillatory movements. It has a large standard deviation particularly due to the relatively weak dependence of the $\mathrm{Cl} \cdots \mathrm{O}$ distances on internal rotation when $\alpha \approx 0^{\circ}$ (see Fig. 2). The 30\% of a gauche conformation with $\alpha=131^{\circ}$ and the remaining $14 \%$ of a conformation with $\alpha=79^{\circ}$ may account for unessigned lines in the microwave spectrum [4]. The presence of at least two conformations is also indicated in an infrared spectroscopic study [11] of the $\mathrm{C}=\mathrm{O}$ stretch frequency in very diluted $\mathrm{CCl}_{4}$ solution, where two separated bands were found at 1794 and $1676 \mathrm{~cm}^{-1}$. In order to understand the conformations found in our experiments, we performed some CNDO/2 calculations [12] . The molecular energy computed as function of the internal rotational angle $\alpha$, with all other geometry parameters kept constant at our experimental values, is shown in Fig. 3. Also shown in this figure is the conformational distribution calculated from this energy curve using Boltzmann statistics, viz. the curve

$$
P(\alpha)=\exp [-\mathrm{V}(\alpha) / R T] / \int_{0}^{2 \pi} \exp [-\mathrm{V}(\alpha) / R T] \mathrm{d} \alpha
$$

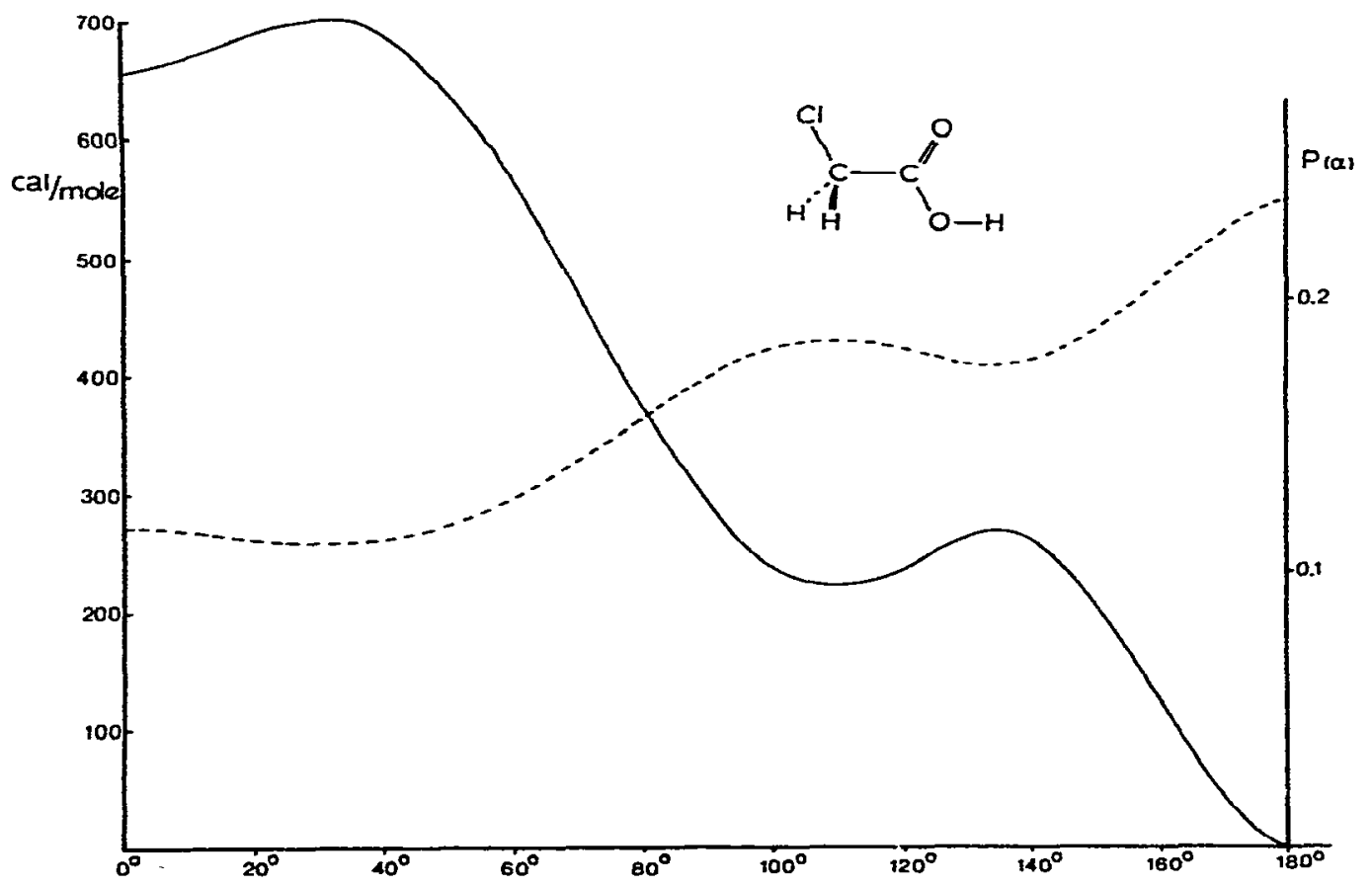

Fig. 3. (-) Molecular energy of monochloroacetic acid as function of the internal rotation angle $\alpha$, calculated by $C N D O / 2(--) ; P(\alpha)$, distribution curve of the conformations, calculated by means of Boltzmann statistics from this energy. 


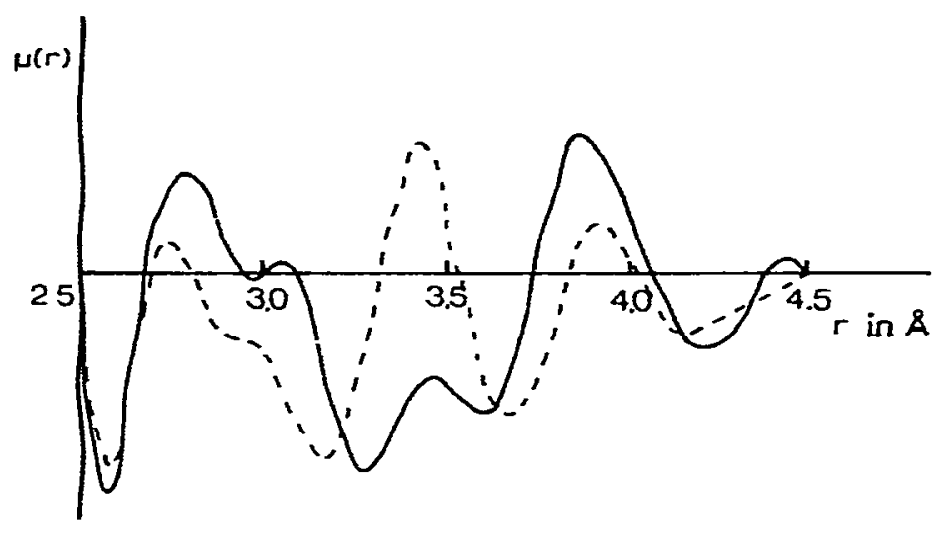

Fig. 4. Part of radial distribution curve for monochloroacetic acid $(\longrightarrow$ ) observed, $(\longrightarrow)$ calculated for CNDO/2 - distribution.

It is seen that according to $\mathrm{CNDO} / 2$ theory, the conformation with $\alpha=180^{\circ}$ should occur in the largest proportion.

A calculated radial distribution curve, assuming this distribution, shows a bad agreement (see Fig. 4) with the experimental RDF. We attribute this to failure of the CNDO/2 approximation for second row elements when repulsion plays an important part.

\section{ACKNOWLEDGEMENTS}

Many thanks are due to Mr. G. Renes of the Rijksuniversiteit of Leiden for his kind and careful supervision of the experimental part of this work, and to Dr. B. P. van Eijck and Dr. A. B. A. van de Berg for their help and interest. We are greatly indebted to F.O.M.R.E. for putting the apparatus at our disposal.

\section{REFERENCES}

1 B. P. van Eijck, G. van der Plaats and P. H. van Roon, J. Mol. Struct., 11 (1972) 67.

2 J. L. Derissen, J. Mol. Struct., 7 (1971) 67, 81.

3 J. M. J. M. Bijen and J. L. Derissen, J. Mol. Struct., 27 (1975) 233.

4 B. P. van Eijck, A. A. J. Maagdenberg and J. Wanrooy, J. Mol. Struct., 22 (1974) 61.

5 W. Zeil, J. Haase and L. Wegmann, Z. Instrumentenk., 74 (1966) 84.

6 J. Murata, K. Kuchitsu and M: Kimura, Jap. J. Appl. Phys., 9 (1970) 591. 
7 B. Andersen, H. M. Seip, T. G. Strand and R. Stölevik, Acta Chem. Scand., 23 (1969) 3224.

8 H. L. Cox and R. A. Bonham, J. Chem. Phys., 47 (1967) 2599.

9 H. M. Seip, T. G. Strand and R. Stölevik, Chem. Phys. Lett., 3 (1969) 617.

10 K. Kuchitsu, T. Fukuyama and Y. Morino, J. Mol. Struct., 1 (1967-8) 463.

11 J. M. J. M. Bijen, Thesis, Conformation and internal hydrogen bonding. Investigation of derivatives of formic acid and acetic acid in the vapour, Rijksuniversiteit Utrecht, 1974.

12 P. A. Dobosch, CNDO and INDO Molecular Orbital Programme, QCPE 142, Indiana University, Bloomington, 1974. 